\title{
Potential impact of climate-related changes is buffered by differential responses to recruitment and interactions
}

\author{
Bruce A. Menge, ${ }^{1,6}$ Sally D. Hacker, ${ }^{1}$ Tess Freidenburg, ${ }^{2}$ Jane Lubchenco, ${ }^{1}$ Ryan Craig,,${ }^{1}$ Gil Rilov,${ }^{3}$ \\ Mae Noble, ${ }^{4}$ and Erin Richmond ${ }^{5}$ \\ ${ }^{1}$ Department of Zoology, Oregon State University, Corvallis, Oregon 97331-2914 USA \\ ${ }^{2}$ MPA Monitoring Enterprise, California Ocean Science Trust, 1330 Broadway, Suite 1135, Oakland, California 94612 USA \\ ${ }^{3}$ Department of Biology and Biotechnology, National Institute of Oceanography, Israel Oceanographic and Limnological Research \\ (IOLR), P.O. Box 8030, Haifa 31080 Israel \\ ${ }^{4}$ Red Sea Research Center, 4700 King Abdullah University of Science and Technology (KAUST), Building 2, Office \#3216-W4, \\ Thuwal 23955-6900 Saudi Arabia \\ ${ }^{5}$ Alaska Fisheries Science Center, 7600 Sand Point Way NE, Seattle, Washington 98115 USA
}

\begin{abstract}
Detection of ecosystem responsiveness to climatic perturbations can provide insight into climate change consequences. Recent analyses linking phytoplankton abundance and mussel recruitment to the North Pacific Gyre Oscillation (NPGO) revealed a paradox. Despite large increases in mussel recruitment beginning in 2000, adult mussel responses were idiosyncratic by site and intertidal zone, with no response at one long-term site, and increases in the low zone ( $1.5 \%$ per year) and decreases in the mid zone $(1.3 \%$ per year) at the other. What are the mechanisms underlying these differential changes? Species interactions such as facilitation by barnacles and predation are potential determinants of successful mussel colonization. To evaluate these effects, we analyzed patterns of barnacle recruitment, determined if predation rate covaried with the increase in mussel recruitment, and tested facilitation interactions in a field experiment. Neither magnitude nor season of barnacle recruitment changed meaningfully with site or zone from the 1990s to the 2000s. In contrast to the relationship between NPGO and local-scale mussel recruitment, relationships between local-scale patterns of barnacle recruitment and climate indices were weak. Despite differences in rates of prey recruitment and abundance of sea stars in 1990-1991, 1999-2000, and 20072008, predation rates were nearly identical in experiments before, during, and after 1999-2000. The facilitation experiment showed that mussels $M$. trossulus only became abundant when barnacle recruitment was allowed, when abundance of barnacles reached high abundance of $\sim 50 \%$ cover, and when mussel recruitment was sufficiently high. Thus, in the low zone minimal changes in mussel abundance despite sharply increased recruitment rates are consistent with the hypothesis that change in adult mussel cover was buffered by the relative insensitivity of barnacle recruitment to climatic fluctuations, and a resultant lack of change in facilitation strength. Facilitation of mussels is likely important in the mid zone as well, but the dynamics of the longer-lived M. californianus at our two long-term sites appeared to be driven primarily by differential regimes of disturbance. Although rocky intertidal ecosystems may be sensitive to major climatic perturbations, predicting community responses will be difficult due to complex individualistic responses of key taxa during the recruitment stage and their influences on subsequent species interactions.
\end{abstract}

Key words: barnacles; climate change; coastal ecosystem; facilitation; mussels; Oregon; predation; recruitment; rocky intertidal; species interactions.

\section{INTRODUCTION}

The ultimate concern regarding climate change is how Earth's ecosystems will respond, knowledge of which remains limited (Hoegh-Guldberg and Bruno 2010). Clues to possible responses can be inferred from the ecological impacts of climatic variation such as El NiñoSouthern Oscillation (ENSO), Pacific Decadal Oscilla-

Manuscript received 2 August 2010; revised 12 January 2011; accepted 31 January 2011. Corresponding Editor: E. D. Grosholz.

${ }^{6}$ E-mail: mengeb@oregonstate.edu tion (PDO), and the North Pacific Gyre Oscillation (NPGO), but community or ecosystem responses to these shifts have been hard to identify. For example, although coral and kelp communities have shown clear responses to ENSO (Tegner and Dayton 1987, Glynn 1988), no influence of the 1983-1984 El Niño was detected in the rocky intertidal communities of Tatoosh Island (Paine 1986), a site of decades-long intensive ecological research. In contrast, the upper limit to the mussel zone on the shore in these same ecosystems seems to have responded to very long-term cycles associated with celestial events such as an 18.6-year oscillation in lunar orbital inclination (Denny and Paine 1998). In 
another example, along the central Oregon coast, the 1997-1998 El Niño was associated with sharp decreases in intertidal kelp abundance and growth rates (T. Freidenburg, G. Allison, and B. Menge, unpublished data). On the central and northern California coast, the 1997-1998 ENSO coincided with an increase in the rate of recruitment of barnacles to rocky shores (Connolly and Roughgarden 1999). Finally, along the Oregon coast, growth of the California mussel over the past two decades has varied with both ENSO and PDO, with the warmer water and higher food (phytoplankton) conditions of these events associated with faster growth (Menge et al. 2008).

Mixed clues are offered by the very small number of studies that have examined community responses to environmental changes that mimic those forecast under climate-change scenarios. For example, in a coastal site bathed by water warmed by a power plant, shifts in the macrophyte assemblage occurred that were complex and unexpected based on simple responses to temperature (Schiel et al. 2004). In a shallow subtidal Mediterranean system, structure shifted from a calcifier-dominated assemblage to an assemblage dominated by fleshy macrophytes along a $\mathrm{pH}$ gradient created by a $\mathrm{CO}_{2}$ seep (Hall-Spencer et al. 2008). In a Pacific Northwest rocky intertidal community, an apparent decline in $\mathrm{pH}$ in the 2000s was associated with differential responses by calcifiers, with some (mussels) decreasing in abundance and others (barnacles, calcifying algae) not (Wootton et al. 2008).

Here we examine the response of rocky intertidal communities to previously reported, climate-related changes in the inputs of mussel larvae that occurred in 1999-2000 (hereafter referred to as the "millennial transition; see Menge et al. 2009). We focus specifically on the factors likely to underlie the relatively low sensitivity of ecologically dominant mussels (primarily Mytilus californianus in the middle intertidal zone and $M$. trossulus in the low zone) to orders-of-magnitude increases in the input of mussel settlers.

Natural history background.-Our studies of rocky intertidal communities in Oregon began in 1983, producing a 26-year period of continuous observations and experiments spanning the 1997-2000 period during which major shifts in both ENSO and PDO occurred. Patterns of community structure have been documented during this entire period, and over time we have added programs of quantification of recruitment patterns (starting 1989), phytoplankton concentration (starting 1993), and other coastal oceanographic conditions (e.g., temperature, currents; late 1990s). Experiments examining species interactions carried out during the same time period (e.g., Menge et al. 2004) help to inform our interpretations of the likely links between these different components.

Rates and patterns of succession along the Oregon coast are generally similar to those observed by Paine and Levin (1981) and Wootton $(1994,2002)$ on Tatoosh
Island, Washington (Guichard et al. 2003; B. Menge, personal observations). In the mid zone, the basic successional sequence on rock surfaces cleared by winter storms is Balanus glandula followed by $M$. trossulus followed by $M$. californianus, with Pollicipes polymerus and Semibalanus cariosus sometimes settling in the early stages with B. glandula and M. trossulus. The presence of these latter two species is very patchy, however, and succession often occurs without them. The eventual dominance of $M$. californianus (after about seven to eight years at Tatoosh) is likely due to their better antipredator (primarily whelks in the mid zone) defenses (e.g., thick shell) and longer life relative to the thinshelled, shorter-lived M. trossulus (Wootton 2002, Sanford and Worth 2009, 2010). Studies on the Oregon coast have shown that rates of recovery after disturbance vary with food availability for mussels (i.e., phytoplankton abundance; Guichard et al. 2003, Menge et al. 2008). At more productive sites such as Strawberry Hill (SH), recovery to $M$. californianus dominance after disturbance takes about two to three years, while at less productive sites such as Boiler Bay (BB), recovery takes about seven to eight years.

Most of the time, mussels rarely survive in the low intertidal, where sea stars and whelks eliminate them (e.g., Paine 1966, 1974, Dayton 1971, Menge et al. 1994, Navarrete and Menge 1996; see Paine and Trimble 2004 for a partial exception). On the Oregon coast, filterfeeding sessile invertebrates can occupy substantial amounts of space at sites with high rates of recruitment and/or high food availability (e.g., Menge et al. 1994, 2004). At such sites, succession can take several contrasting pathways, is short (usually $<1 \mathrm{yr}$ ), and is strongly modified by predation (e.g., Navarrete et al. 2000). In invertebrate-dominated patches, bare rock surfaces tend to be rapidly colonized by barnacles (both B. glandula and C. dalli) in early fall, and these generally attract predators (sea stars and whelks), which tend to differentially eliminate $B$. glandula leaving the less attractive prey $C$. dalli as the dominant space occupier (Menge 2003). Predation pressure is patchy, however, and if high covers of barnacles persist into later fall, $M$. trossulus colonizes and smothers the barnacles. Over winter and into the following spring and summer, predators discover and eliminate these mussel patches, restarting the process (e.g., Menge et al. 1994). At such sites, gooseneck barnacles, the giant barnacle B. nubilus, and $M$. californianus, all large and more resistant to predators, sometimes become patchily abundant as well, often persisting for several years (B. Menge; personal observations). Thus, the low intertidal is a mosaic of macrophytes; fast-cycling, predator-susceptible, sessile invertebrates (i.e., small mussel and barnacle species); and slow-cycling, predator-resistant, sessile invertebrates (i.e., large barnacle and mussel species, anemones).

Colonization of rocky shores by mussels is dependent on prior occupation of rock surfaces by certain 
facilitators, including filamentous algae such as Endocladia muricata, the byssal threads of established mussels, and acorn barnacles (Paine 1974, Menge 1976, Berlow 1997, Bertness et al. 2006). Colonization of bare rock surfaces by mussels almost never occurs, and has been observed only when the rock substratum is highly rugose, but even under these conditions rarely occurs (B. Menge, personal observations). Facilitation of $M$. trossulus by barnacles has been observed in the mid intertidal zone along the Oregon and Washington coasts (Berlow 1997, Wootton 2002) and is common in the low zone at some sites in Oregon (e.g., Navarrete et al. 2000).

Against this spatiotemporal background of ecological dynamics, our goal in this paper is to understand why large increases in mussel recruitment in the 2000s did not lead to higher mussel abundances. To address this goal, across the millennial transition, we (1) document spatiotemporal patterns of abundance of mussels and barnacles, (2) evaluate decadal-scale differences in recruitment of mussels and barnacles, (3) compare predation rates, and (4) examine the role of facilitation by barnacles in determining mussel abundance. We use these data to evaluate two hypotheses:

$H_{1}$. - Predation increased in the 2000s, leading to higher post-recruitment mortality of mussels.

$\mathrm{H}_{2}$.- In contrast to mussels, recruitment of barnacles did not change, and thus facilitation of mussels by barnacles did not change.

\section{Methods}

Study sites.- Studies of the longest duration (1983present) were carried out at sites located on two capes, about $65 \mathrm{~km}$ apart on the central Oregon coast. The site at the northern Cape Foulweather (hereafter CF) was Boiler Bay (hereafter BB; 44⒋ $49^{\prime} 48^{\prime \prime} \mathrm{N}, 124^{\circ} 3^{\prime} 36^{\prime \prime} \mathrm{W}$ ) and that at the southern Cape Perpetua (hereafter CP) was Strawberry Hill (hereafter SH; $44^{\circ} 15^{\prime} \mathrm{N}, 124^{\circ} 7^{\prime} 12^{\prime \prime}$ W; see Appendix A: Fig. A1 for a map of sites). General patterns of zonation at all sites considered here are typical of wave-exposed northeastern Pacific shores (e.g., Paine 1966, 1974, Menge et al. 1994, 2004, Wootton 1994, 2002), with a high zone dominated by barnacles (Balanus glandula, Chthamalus dalli) and fucoid algae (mostly Pelvetiopsis), a middle zone dominated by mussels (Mytilus spp.) and gooseneck barnacles (Pollicipes polymerus), and a low zone dominated mostly by a diverse assemblage of macrophytes. Spatial variation occurs at local and regional scales, but is greatest in the low intertidal. For example, low-zone sites at $\mathrm{CF}$ have higher abundances of algae than at $\mathrm{CP}$ and low-zone sites at $\mathrm{CP}$ have higher abundances of sessile and mobile invertebrates and more free space than at CF (Menge 1992, Menge et al. 1994, 1997a, 2004, Kavanaugh et al. 2009). To expand the spatial coverage of the coast and increase resolution, eight additional sites were added in the mid to late 1990s (see Appendix A: Fig. A1). These include additional sites at CF (Fogarty Creek or FC and Manipulation Bay or $\mathrm{MB}$; each about $0.5 \mathrm{~km}$ from $\mathrm{BB}$ ) and $\mathrm{CP}$ (Yachats Beach or YB and Tokatee Klootchman or TK; each 3 $\mathrm{km}$ from $\mathrm{SH}$ ).

Community structure.-Abundance of sessile and mobile invertebrates was quantified using the transectquadrat method. The protocol involves sampling 10 randomly placed, $0.25-\mathrm{m}^{2}$, PVC-frame quadrats placed along a $30-50 \mathrm{~m}$ transect tape run through the middle of the high, mid, and low intertidal $(\sim+2.5,1.8$, and $0.2 \mathrm{~m}$ above mean lower low water, respectively) zones parallel to the water's edge, with one transect per zone per site (e.g., Menge 1976, Menge et al. 1994). Transect locations were not fixed but within zones the same section of shore $(\sim 100 \mathrm{~m}$ in length) was sampled each time. Estimates of percent cover of sessile organisms are based on summing across cover estimates in 25 subquadrats in each quadrat, each a $10 \times 10 \mathrm{~cm}$ square, which occupies $4 \%$ of the total surface area of the quadrat area. When organisms occur in layers, we made separate estimates for canopy cover (cover of mostly tall $[>10 \mathrm{~cm}]$ macrophytes), understory cover (cover of shorter $[<10 \mathrm{~cm}]$ macrophytes), and primary space cover (cover of sessile invertebrates, macrophyte crusts, holdfasts or rhizomes, and bare rock).

The community surveys were carried out by students in a marine biology course, taught annually in spring since 1980 at Oregon State University's Hatfield Marine Science Center (HMSC). Under the direction of the lead author, students were trained in the techniques of transect-quadrat sampling as part of a class project. Sampling occurred in late April or early May. Starting in 1991, sampling was focused on comparing BB and $\mathrm{SH}$. In some years, high waves prevented sampling in the wave-exposed areas so these samples are absent for these years. For the present analysis, data from the remaining samples were filtered carefully to exclude questionable information, yielding the 8-12 surveys shown in Fig. 1. We analyzed mean cover (of 10 replicate sample plots) of each taxon in each year's sample.

Recruitment.-Rates of recruitment of barnacles and mussels were estimated using replicated (five per site) deployments of larval collectors (plastic mesh balls for mussels, settlement plates for barnacles; Farrell et al. 1991, Menge et al. 1994, Barth et al. 2007, Broitman et al. 2008, Sanford and Worth 2010, Witman et al. 2010). Mussel plantigrade larvae attach to the filaments of the mesh balls (SOS Tuffy Pads; Clorox Company, Oakland, California, USA) that mimic the filamentous algal and mussel byssal thread surfaces that constitute common settlement sites in nature (e.g., Paine 1974).

For mussels, we analyzed only individuals between 230 and $280 \mu \mathrm{m}$ in length. This excludes smaller precompetent settlers and larger post-recruitment secondary settlers (e.g., Bayne 1964), so most individuals are likely to have been recruits (e.g., Rilov et al. 2008). Genetic analyses indicate that most (>90\%) mussel recruits in our collectors are Mytilus trossulus with the 

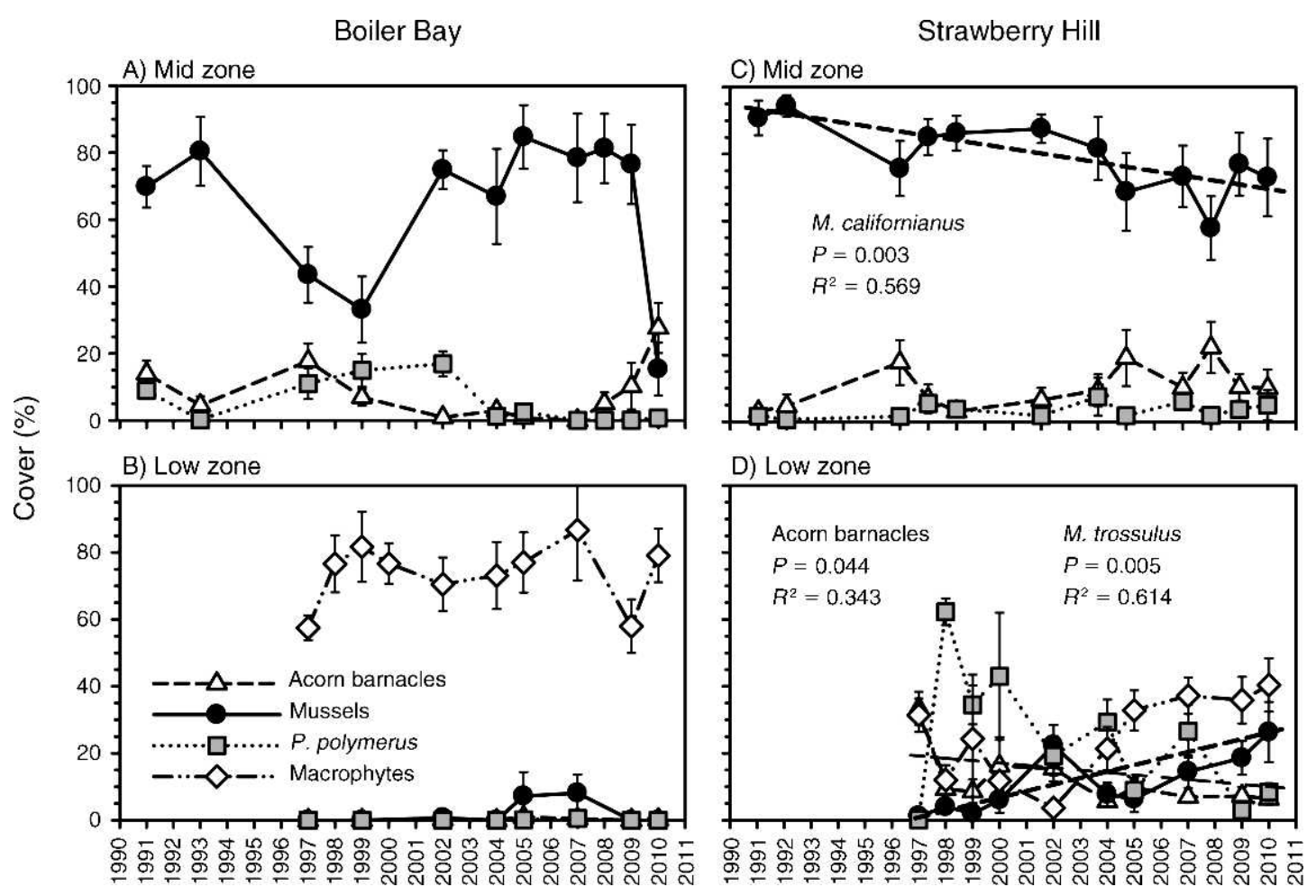

FIG. 1. Changes in abundance of mussels, acorn barnacles (ac. barn.; B. glandula and C. dalli), macrophytes, and gooseneck barnacles (Pollicipes polymerus) in the mid and low intertidal zones at Boiler Bay (BB) and Strawberry Hill (SH) from 1991 to 2010. Data are mean percent cover and error bars show \pm SE. Probabilities and $R^{2}$ for significant linear regressions of abundances of mussels (Mytilus californianus and Mytilus trossulus) are shown; regressions for all other taxa at BB and SH were not significant $(P$ $>0.05)$. See Appendix B: Table B 1 for details of regression analyses.

remainder consisting of M. californianus (P. Raimondi and B. Menge, unpublished data).

Barnacle recruitment was estimated using $10 \times 10 \mathrm{~cm}$ PVC plastic plates that are coated on the upward-facing side with Saf-T-Walk (3M, Minneapolis, Minnesota, USA), a uniformly textured rubbery surface that provides the shallow depressions preferred by barnacles for settlement (e.g., Farrell et al. 1991, Menge et al. 2003, Witman et al. 2010). Collectors were returned to the laboratory where recruits were identified and counted under a dissecting microscope. Monthly samples were initiated in July 1989 at BB and SH; the number of sites sampled increased starting in 1993 to a maximum of 10 sites from 2001 on. At BB and SH only, collectors were deployed in both mid and low intertidal zones while at all other sites, collectors were in the mid zone. The month-long deployment of these collectors means that the collected juveniles include both settlers (individuals that have settled within the last 24-48 h) and recruits (individuals that settled between $\sim 2$ to 30 days prior to collection; Connell 1985). For barnacles, individuals (attached cyprids) that had not yet completed metamorphosis are termed "settlers" and metamorphosed small barnacles are termed "recruits." Barnacle recruits were identified to species. For both mussels and barnacles, we refer to recruits that have survived and grown in the adult habitat for more than one month as "colonists." Our basic unit of analysis was average persite monthly recruitment by zone, standardized to daily rates per collector.

Climate-recruitment relationships.-In Menge et al. 2009, we explored the relationship between chlorophyll $a$ (i.e., phytoplankton abundance) and mussel recruitment, and three climatic indices, the multivariate El Niño-Southern Oscillation index (MEI), PDO, and the NPGO, using a simple linear-regression approach. These analyses suggested that mussel recruitment is influenced by PDO and particularly NPGO, but nonetheless explained only about $2-13 \%$ of the variance. To allow comparisons between the analysis presented in Menge et al. 2009, here we also present the results of loglinear regression analyses comparing the three climate indices to recruitment of B. glandula and $C$. dalli.

Predation rates.-Rates of predation can be expressed as per population (mortality rates of prey in the presence of predators) or per capita (per population rates standardized by predator density). To determine the (per population) rates at which predators, mostly sea stars Pisaster ochraceus, removed mussels (M. californianus) from the low intertidal zone (in the mid intertidal $P$. ochraceus is generally rare and its predation impact is negligible), we carried out predation-rate 
experiments in 1990, 1991, 1999, 2000, 2007, and 2008. $M$. californianus $(\sim 4 \mathrm{~cm}$ in length) were transplanted from the mid to the low intertidal zone in May/June each year the experiment was done, held against the rock with plastic vexar mesh (Memphis Net and Twine, Memphis, Tennessee, USA) for six to eight weeks to allow reattachment, and then exposed to (control, partial fence) or protected from (exclusion, complete fence) predators (e.g., Menge et al. 2004). Five replicates were established per site. Rates of decrease from the original number of 50 were estimated from biweekly counts of surviving mussels in each treatment across five replicates per site. These data were used to calculate the rate of mussel mortality using regression analyses on each replicate (number surviving vs. day of experiment) to calculate a slope (rate of loss). Rates were adjusted for mortality in controls which was typically very low (a few percent). Monitoring of each replicate was terminated when the number of mussels surviving dropped to 0 . Experiments were monitored through the following December-January. These experiments thus provide a measure of the capacity of the sea star population at a site to remove mussels. Although we did not test rates of removal of the smaller $M$. trossulus, prior experiments have shown that between-site differences in sea star predation rates (and per population interaction strength) are similar to those we document below (Navarrete and Menge 1996).

Sea star density.-We were unable to carry out predation-rate experiments in all years of the study, but at sites of similar wave exposure, predation rates are likely to reflect abundance of predators (e.g., Menge et al. 2004). We estimated density of $P$. ochraceus using belt transects, first in 1991, and annually from 1998 on. Transect tapes, varying between 10 and $30 \mathrm{~m}$ in length, were laid out parallel to the water's edge in the low, wave-exposed zones at $\mathrm{BB}$ and $\mathrm{SH}$ just below the lower edge of the mussel bed. Counts of the number of sea stars were made in a replicated $(n=2-5) 2 \mathrm{~m}$ wide "belt" along the shore below this transect tape. Counts were made one to three times per year, from April to August, which is the period of peak $P$. ochraceus activity (Mauzey 1966, Paine 1966, 1974; B. Menge, personal observation).

Facilitation experiment.-To evaluate the influence of facilitation on abundance of M. trossulus, in 2006-2008 we carried out an experiment in the low zone that quantified the abundance of mussels and barnacles ( $B$. glandula and $C$. dalli) colonizing in the presence (+barnacle) and absence (-barnacle) of barnacle recruits. In this experiment, barnacles were manually removed using knife tips or small scrapers during biweekly to monthly monitoring visits, weather permitting (e.g., Menge 1976, Berlow 1997). During succession, barnacles routinely colonize the rocks prior to mussels (e.g., Dayton 1971, Paine and Levin 1981, Berlow 1997, Menge 2003). Experiments were carried out at six sites on the two capes $(\mathrm{CF}$ : FC, BB, MB; CP:
YB, SH, TK), with five replicates per site, and were initiated by manually clearing all organisms in $15 \times 15$ $\mathrm{cm}$ plots, and then applying oven cleaner (lye) to remove encrusting algae. Each plot was marked with four lag screws at each corner. Note that predators (sea stars and whelks) had access to all plots. Changes in abundance were documented using digital photographs of each plot during each subsequent visit. Abundances (percent cover) of sessile invertebrates and macrophytes were estimated by visual inspection of each photograph (e.g., Dethier et al. 1993). We report data for B. glandula, $C$. dalli, M. trossulus, and total macrophyte cover. Cover of barnacles in -barnacle treatments reflects abundances observed prior to removal of recruits.

Data analysis.-Data were analyzed using JMP 8.0 (SAS Institute, Cary, North Carolina, USA). Data were log-transformed (densities; $\ln (x+1)$ ) or arcsine-transformed (percent covers, proportions; $\arcsin \sqrt{x}$, where $x$ is expressed as a proportion) prior to analysis. Residuals were examined visually for evenness of distribution. When multiple sites were included in an ANOVA analysis, site was analyzed as a random effect; all other factors were regarded as fixed.

Three-way nested analysis of variance (ANOVA) was used to determine the separate and joint effects of decade, zone, and site, with year nested within decade, on recruitment of $B$. glandula and $C$. dalli, and the effects of year, site, and treatment on mussel survival in predation-rate experiments. Two-way nested ANOVA was used to determine effects of decade, site, and year nested within decade on barnacle recruitment across six sites. Repeated-measures ANOVA was used to test the effects of site and barnacle recruitment on species abundances in the facilitation experiment. In repeatedmeasures ANOVA, all factors are considered to be fixed. Regression analysis was used to determine the patterns of temporal change in abundances of community components and in abundances of $M$. californianus and M. trossulus from 1991 to 2010.

\section{RESULTS}

Community structure.-In the mid zone, abundance of acorn barnacles (mostly B. glandula and C. dalli), and gooseneck barnacles ( $P$. polymerus) persisted at similar abundances at $\mathrm{BB}$ and $\mathrm{SH}$, showing no temporal trend (Fig. 1; linear regressions, see Appendix B: Table B1). In contrast, mussel (primarily $M$. californianus; see Appendix A: Fig. A2, Appendix B: Table B2) abundance at BB dropped sharply during 1997-1999 (to 30-40\% from $70-90 \%$ ), and again during 2009-2010 (to $\sim 15 \%$ from $\sim 80 \%$; Fig. 1A). Despite these large changes, at BB no long-term trend in mussel abundance was observed (Appendix B: Table B1, B2). At $\mathrm{SH}$, mid-zone $M$. californianus abundance declined at a rate of $\sim 1.3 \%$ cover/yr (Fig. 1C; see Appendix A: Fig. A2 and Appendix B: Table B2 for details of analysis). The large drops at BB coincided with ENSO-associated severe 


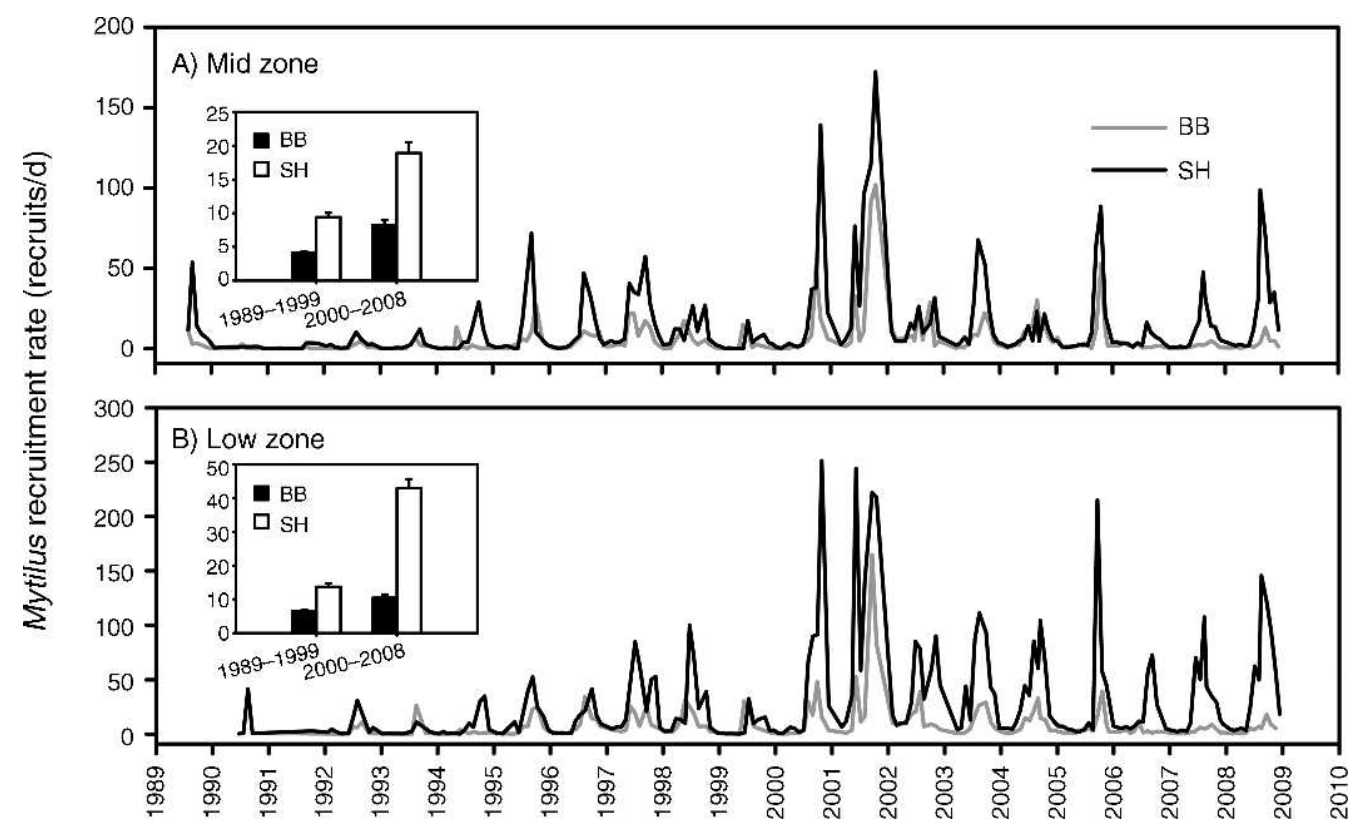

FIG. 2. Rates of recruitment of mussels per day (mean + SE) in the (A) mid zone and (B) low zone from 1989 to 2009 at Boiler Bay and Strawberry Hill. Insets show decadal averages (1989-1999 vs. 2000-2008) for each site and zone. See Appendix B: Table B3 for statistical details.

winters (the 1997-1999 El Niño/La Nina and 2009-2010 El Niño). Such large changes were not seen at SH.

In the low zone at $\mathrm{BB}$, abundances of macrophytes and sessile invertebrates were consistently high and low, respectively, while at $\mathrm{SH}$, the reverse pattern occurred (Fig. 1B, D). At SH but not BB, abundance of mussels (a mix of M. californianus and M. trossulus; Appendix A: Fig. A2, Appendix B: Table B2) increased from 1997 onward at a rate of $\sim 1.5 \%$ per year (Fig. 1B, D). Abundances of barnacles and macrophytes showed no temporal trend (linear regressions, Appendix B: Table $\mathrm{B} 1)$.

Recruitment.-Acorn barnacles can facilitate recruitment of mussels (Menge 1976, Navarrete and Castilla 1990, Berlow 1997, Bertness et al. 2006), so we compared inter-decadal changes in mid- and low-zone mussel and barnacle recruitment over the same time span at $\mathrm{BB}$ and $\mathrm{SH}$, the sites with the longest time series (e.g., Menge et al. 2009). For mussels, large increases occurred by site, zone, and decade (Fig. 2, Appendix B: Table B3). At BB, inter-decadal increases in mussel recruitment were $1.6 \times$ (low zone) to $2.3 \times$ (mid zone) while at SH increases were $3.2 \times$ (low zone) to $2.2 \times$ (mid zone). In contrast, inter-decadal increases in recruitment of $B$. glandula, though statistically significant, were relatively slight (Figs. 3, 4, Appendix B: Table B3) at $1.1 \times$ the average for the 1990s in the mid zone. Recruitment of $C$. dalli also decreased in the mid zone but in the low zone, inter-decadal change in this barnacle varied with site, increasing at $\mathrm{BB}$ and decreasing at SH (Fig. 5, Appendix B: Table B3).
More broadly, of the six (out of 10 total) sites with mid-zone barnacle recruitment time series that began in the mid-1990s or earlier, only two (SR, SH) had higher B. glandula recruitment in the 2000s (Fig. 3A). Although inter-decadal differences were significant, the total variance explained was modest (Appendix B: Table B4, $11 \%$; two-way ANOVA). The most consistent pattern across all three taxa was substantial among-year variation, a pattern that occurred across both decades (Figs. 2, 4, 5). For B. glandula, inter-decadal differences appeared due primarily to one or a few years with unusually high recruitment (SR, 2008 and SH, 2006, 2007, and 2008; B. Menge, unpublished data). Note that the 1990s data for CM, FC, and CA were limited in extent (e.g., Menge et al. 2009), so inter-decadal trends likely are better reflected by the other three sites (Fig. 3A). Similarly, at these six sites, recruitment of $C$. dalli, a smaller, flatter barnacle than B. glandula, differed among sites, but by decade only at the CM site (Fig. 3B, Appendix B: Table B5). Further, the inter-decadal difference was opposite to that shown by mussel and $B$. glandula recruitment. Note that recruitment of this smaller barnacle tends to be lower than that of $B$. glandula (Fig. 3B). Hence, in comparison to mussels, minimal changes in barnacle recruitment occurred during the 1990s to 2000s transition.

Climate-recruitment relationships.-Recruitment of the two barnacle taxa showed relatively weak relationships with the three climate indices (Fig. 6). This contrasts to mussels, for which recruitment was more strongly related to the NPGO, explaining more than two times the variance explained by the strongest relation- 
ship for barnacles, that of $C$. dalli to the PDO (Fig. 6E). Nonetheless, much variance in recruitment remains unexplained by these large-scale, basin-wide, climatic, sources of variation.

Predation rates.-Experiments before, during, and after the millennial transition suggest that predation rates at $\mathrm{BB}$ and $\mathrm{SH}$ were unchanged over an 18-year period (Fig. 7). At $\mathrm{SH}$, predation was consistently stronger during this period than at BB (Appendix B: Table B6; site effect, $P<0.0001)$, but predation rates were remarkably constant (Appendix B: Table B6; no effect of year as a main effect, $P=0.88$, or in the site $\times$ year interaction, $P=0.77$ ). These consistent rates occurred despite differences in prey input during the three pairs of years (Appendix A: Fig. A3). At both sites, mussel recruitment was higher during the 1999-2000 and 2007-2008 experiments than in 1990-1991. Differences in barnacle recruitment also occurred during some of these pairs of years, so the general picture conveyed is that of persistent rates of predation through time regardless of variable within-site rates of prey input. Between-site differences were also persistent, but in this case, as has been suggested before, between-site differences in predation are likely influenced by between-site differences in rates of prey supply which seem likely to explain among-site differences in predator density (e.g., Menge et al. 1994, 1997, 2004; see next section).

Sea star density.- Predation rate is typically strongly influenced by predator density. As initially reported in previous publications (e.g., Menge et al. 1994, 1997, Navarrete and Menge 1996), density of P. ochraceus was always higher at $\mathrm{SH}$ than at $\mathrm{BB}$, a pattern that more recent data demonstrate has persisted to 2010 (Fig. 8). From 1998 to 2010, variation in sea star density was context dependent, varying by both site and year (Fig. $8)$. Note that the relatively constant rates of predation (Fig. 7) occurred despite often substantial annual to multiyear fluctuations in sea star abundance. For example, similar rates in 1999 and 2000 and in 2007 and 2008 occurred despite declines in sea star density at both sites from 1999 to 2000 and from 2007 to 2008 . This suggests that predation rates may have been a function of both numerical and functional responses, and possibly also inter-annual variations in water temperature. For example, Sanford (1999) has shown in field experiments that predation rates of sea stars are sensitive to upwelling-driven variation in sea water temperature, and that sea stars are less active and feed more slowly when bathed by cold, upwelled water.

Facilitation experiment.-Facilitation is an alternative mechanism to different rates of recruitment to help explain the minimal change in mussel abundance, especially in the low intertidal zone. The small increase in B. glandula recruitment (Figs. 3, 4) and lack of change in $C$. dalli recruitment (Figs. 4, 5) during a period of large increases in mussel recruitment (Fig. 2) is consistent with the idea that successful colonization of $M$. trossulus depends on facilitation by barnacles. The
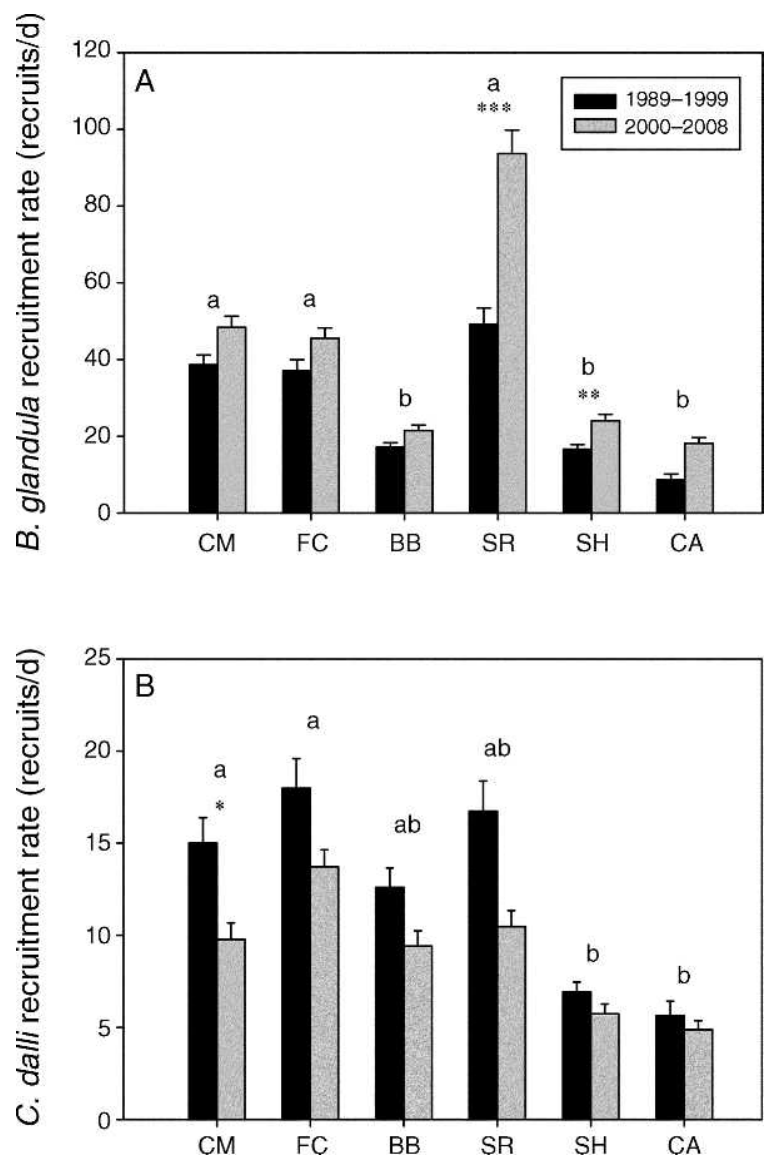

FIG. 3. Rates of recruitment of (A) Balanus glandula and (B) Chthamalus dalli per day (mean + SE) in 1989-1999 vs. 2000-2008 at six sites along the Oregon coast. Sites are arranged north to south from left to right. Lowercase letters above bar pairs indicate among-site differences (pairs with different letters differ at $P<0.01$ ), and asterisks indicate differences between decades. See Appendix B: Tables B4 and B5 for statistical details.

* $P<0.05 ; * * P<0.01$; *** $P<0.001$.

minimal changes in barnacle colonization suggest that the amount of settlement substratum for mussels may have changed little, limiting the abundance of mussels independently of the number of mussel recruits.

The facilitation experiment provided a complex set of results with several surprises (Fig. 9, Appendix B: Table B7). First, in +barnacle treatments at two sites (YB, $\mathrm{SH}), M$. trossulus increased to occupy $\sim 50 \%$ while inbarnacle treatments, no mussels colonized (Fig. 9G-J, Appendix B: Table B7, linear contrasts). Several aspects of this result were unusual: it took two years (rather than a few months in low-zone predator exclusions; B. Menge, personal observations) to occur, it happened despite the presence of predators, and the primary facilitator was C. dalli, not B. glandula (Fig. 9G-J). Second, at the other Cape Perpetua site, TK, no mussels colonized despite the development of a high cover of $C$. dalli in the +barnacle recruit treatment (Fig. 9K, L). 


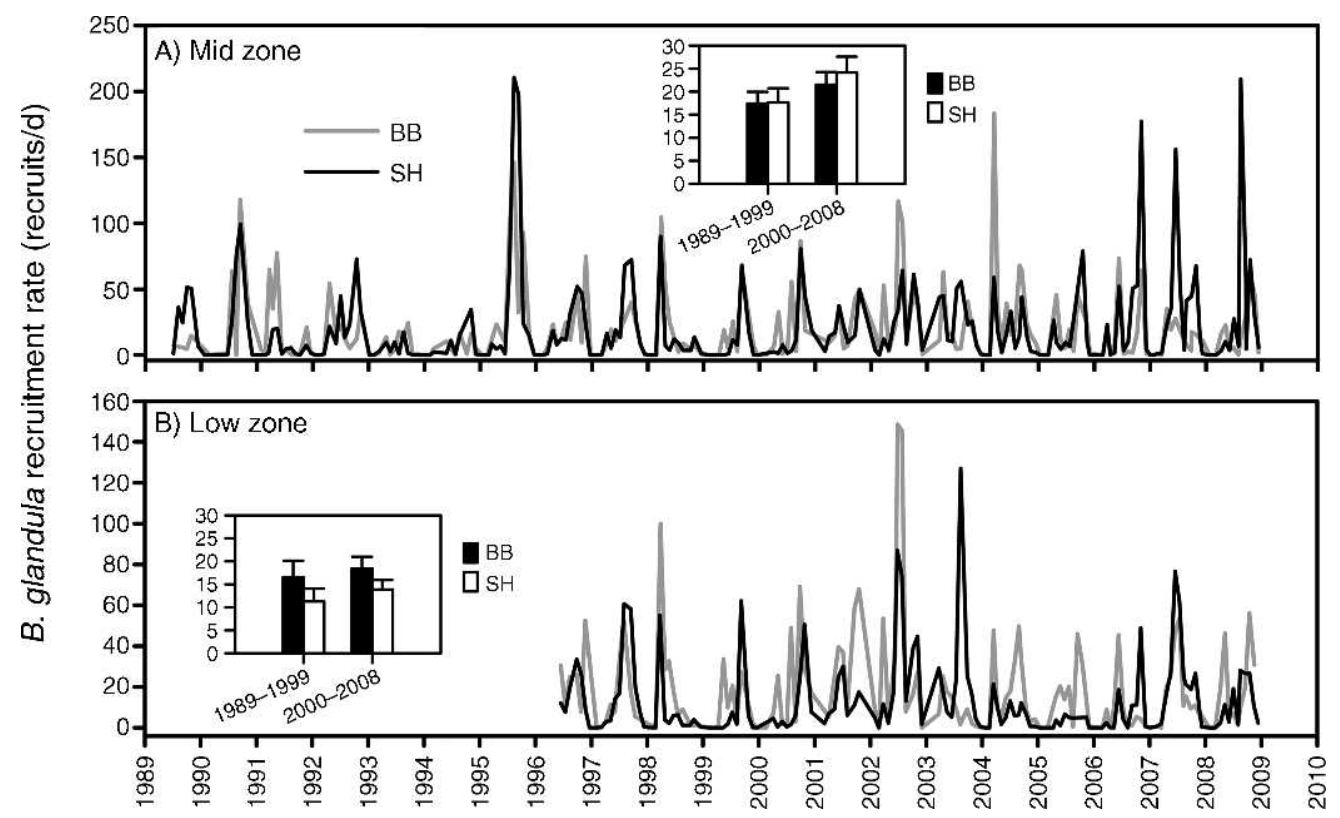

FIG. 4. Rates of recruitment of Balanus glandula per day (mean + SE) in the (A) mid zone and (B) low zone from 1989-2009 at Boiler Bay and Strawberry Hill. Insets show decadal averages (1989-1999 vs. 2000-2008) for each site and zone. See Appendix B: Table B3 for statistical details.

Third, at the Cape Foulweather sites (FC, BB, MB), no mussel colonization occurred (Fig. 9A-F). Instead, macrophytes colonized and dominated space with no effect of barnacle treatment. Thus, the only meaningful effects of removal of barnacle recruits were on mussel colonization (i.e., as would be expected, removal of barnacle recruits led to differences in barnacle abun- dance; see Appendix B: Table B7, linear contrasts), and this occurred at only two of the six sites.

\section{DisCUSSION}

Assuming that the supply of new individuals should lead to higher abundances of adults, the dramatic increase in mussel (Mytilus spp.) recruitment starting

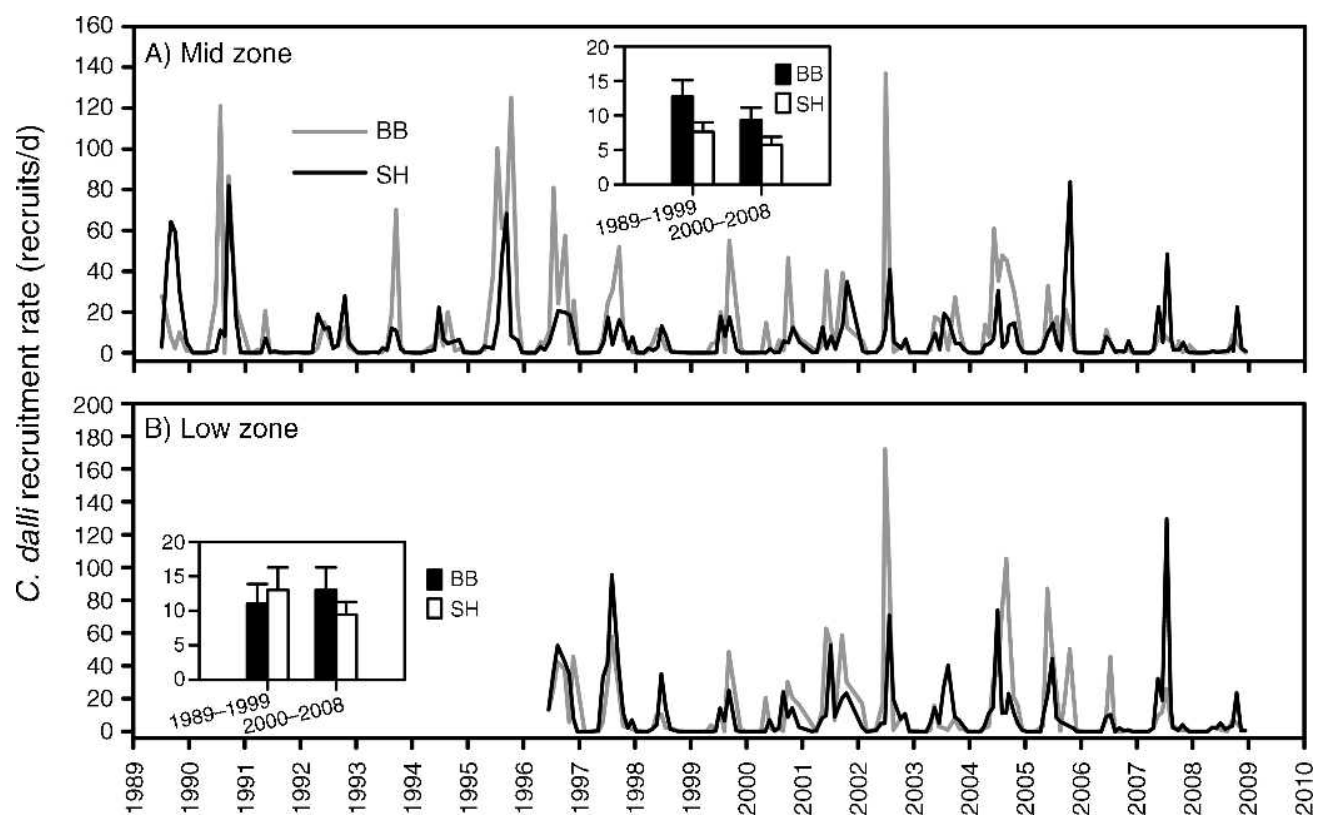

FIG. 5. Rates of recruitment of C. dalli per day (mean + SE) in the (A) mid zone and (B) low zone from 1989-2009 at Boiler Bay and Strawberry Hill. Insets show decadal averages (1989-1999 vs. 2000-2008) for each site and zone. See Appendix B: Table B3 for statistical details. 

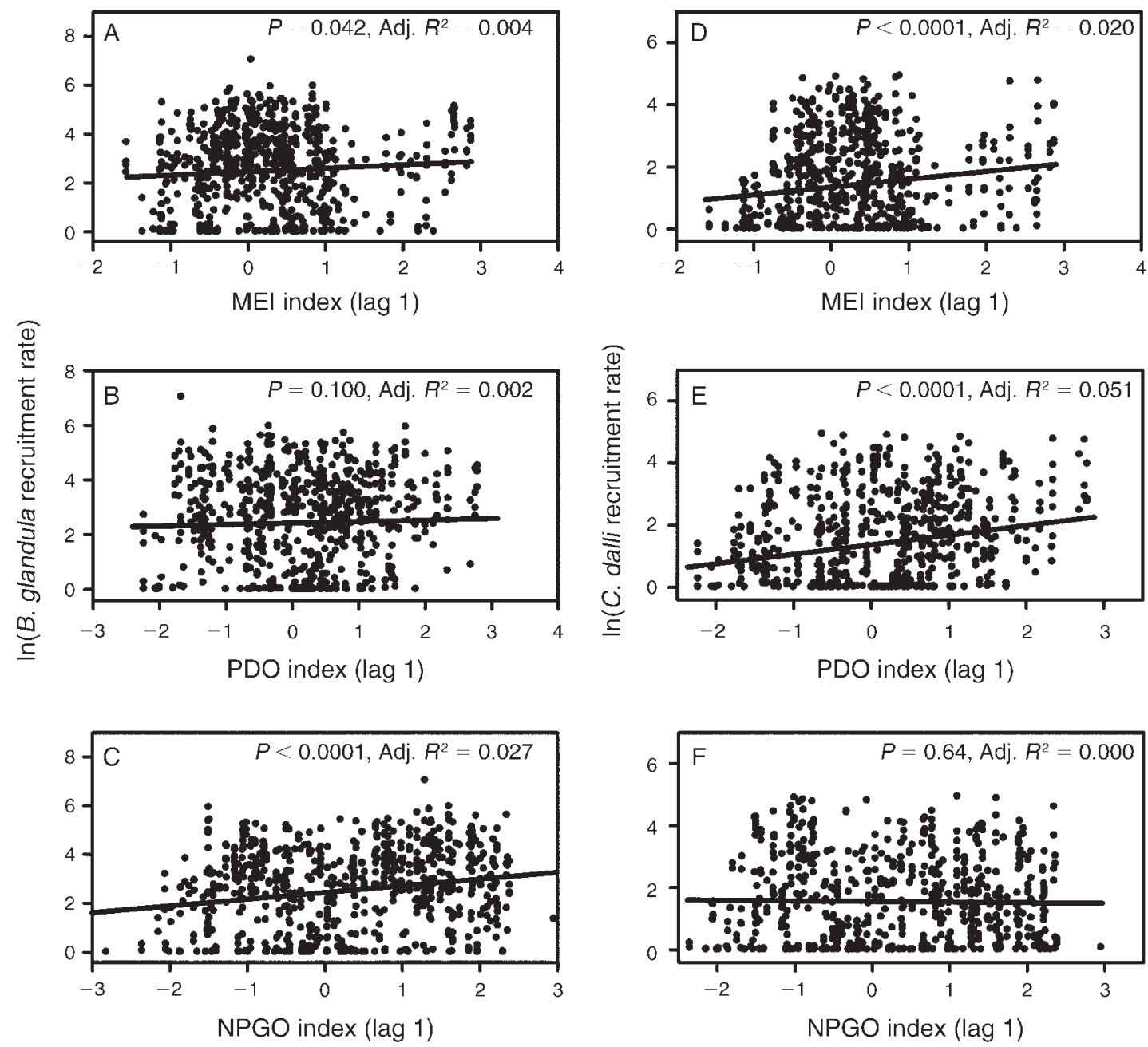

FIG. 6. Relationships between recruitment of B. glandula and C. dalli to climatic variation as expressed in the MEI (multivariate El Niño-Southern Oscillation [ENSO]), Pacific Decadal Oscillation (PDO), and North Pacific Gyre Oscillation (NPGO) indices. ENSO data were obtained from 〈http://cdc.noaa.gov/ENSO/enso.mei_index $\rangle$, PDO data were obtained from $\langle\mathrm{http}: / /$ jisao.washington.edu/pdo/ $/$, and NPGO data were obtained from $\langle\mathrm{http}: / /$ www.ocean3d.org/npgo $\rangle$. In all cases, monthly averages of the indices were matched to monthly recruitment data lagged by one month, assuming that ocean conditions affecting larvae in the water column during one month were those that influenced recruitment in the following month. See Menge et al. (2009, 2011) for further details. Probabilities and adjusted $R^{2}$ s are shown for each log-linear regression in each panel.

in 2000 documented in a previous paper (Menge et al. 2009) suggests that abundance of adult M. californianus and/or M. trossulus should have increased during the 2000s. Community surveys spanning the period 19912010 revealed that, in three of four possible site $\times$ zone combinations, this did not happen (Fig. 1). Only in the low zone at SH did mussels (M. californianus plus $M$. trossulus) increase, and this change was modest, about a $1.5 \%$ increase in cover per year. If the two mussel species are separated, no significant change the abundance of either occurred in the low zone (Appendix A: Fig. A2, Appendix B: Table B2). Why was high mussel recruitment disconnected from, or only weakly linked to, mussel abundance on the shoreline?

We proposed that either or both of two alternative post-recruitment processes could lead to the decoupling of mussel recruitment and mussel abundance: that predation had increased, or that facilitation of mussels by barnacles had not changed, either of which could explain the lack of, or minimal increase in, mussel abundance. Below, we examine the evidence for each alternative.

\section{Hypothesis 1: predation}

Barnacles aren't the only substratum that can facilitate mussels. For example, the turfy red alga Endocladia muricata and the byssal threads of adult mussels have both been shown to attract mussel settlers (Paine 1974). Although these surfaces are primarily available in the mid intertidal, much rock surface in the low intertidal is occupied by turf-forming algae (e.g., the macrophyte categories in Figs. 1 and 9 include large 

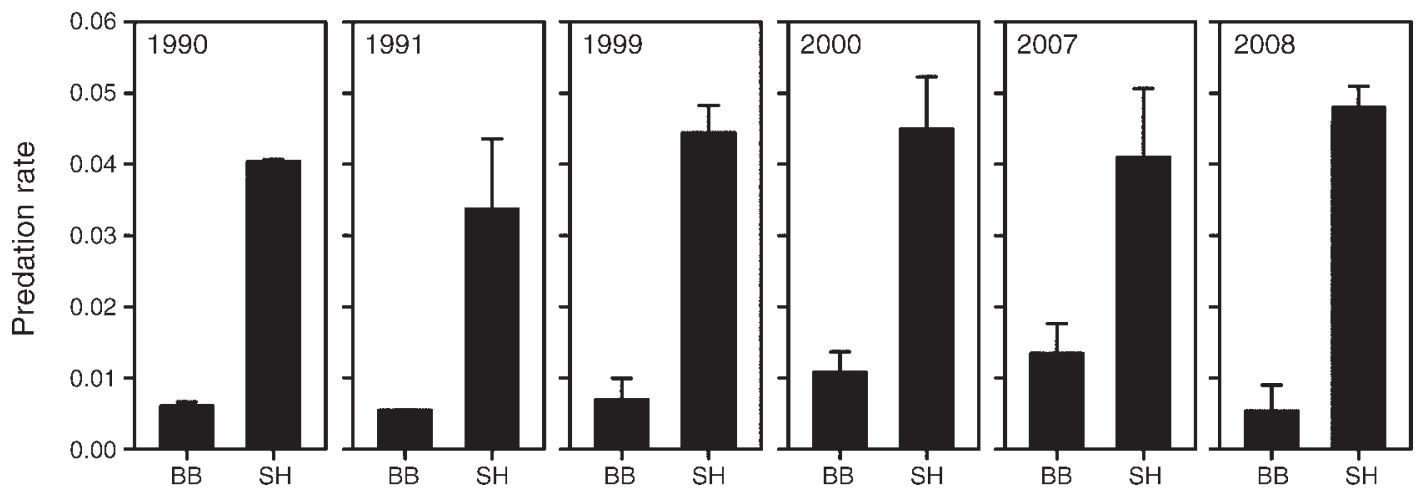

FIG. 7. Rates of predation in 1990, 1991, 1999, 2000, 2007, and 2008 at Boiler Bay and Strawberry Hill. Rates are slopes of loglinear regressions between day of experiment and proportion of mussels surviving to that day. Slopes were calculated for predatorpresent and predator-absent treatments of each replicate. Rates are expressed as the rate of mussel consumption in predator-present plots minus that in predator-absent plots of each, and were multiplied by -1 to make them positive.

fractions of algal turfs), and seem likely to be attractants for larval mussels. Yet, despite mussel recruitment rates at FC that were comparable to those at SH (e.g., Menge et al. 2009; Appendix A: Fig. A4), no mussels colonized macrophyte-dominated plots in the facilitation experiment (Fig. 9). Thus, alternative mechanisms to facilitation may also be important.

Specifically, the lack of response of mussel abundance in the low zone to the large increase in mussel recruitment in the 2000s could result from a corresponding increase in predation. Since the pioneering efforts of Connell (1961) and Paine (1966), predation has been considered to be a preeminent factor in controlling lower distributional limits on rocky shores.
Much evidence supports this interpretation from locations around the world (e.g., Paine 1971, Fairweather et al. 1984, Duran and Castilla 1989, Menge et al. 2003, 2004, Navarrete et al. 2005). In our system, we have previously demonstrated that the rate of sea star predation on mussels in the low zone at BB was less than at SH (M. californianus [Menge et al. 1994, 2004], M. trossulus [Navarrete and Menge 1996]). Contrary to hypothesis $H_{1}$, however, sea star predation rates were evidently insensitive to variation in input of new mussel recruits. Predation rates in 1990-1991 were virtually identical to those in 1999-2000 and 2007-2008 (Fig. 7, Appendix B: Table B6). Further, although sea star densities at each site have varied through time (Fig. 8),

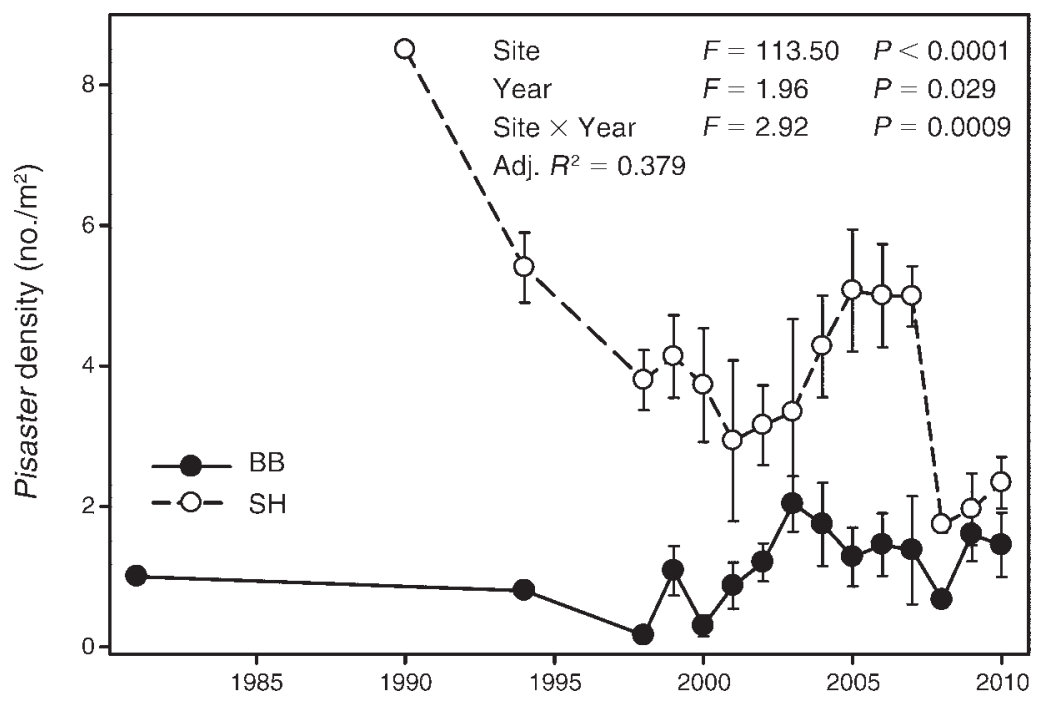

FIG. 8. Density of Pisaster ochraceus in the low, wave-exposed, intertidal Boiler Bay and Strawberry Hill, 1991-2010. Data were from replicated belt transects (area ranging from 10 to $60 \mathrm{~m}^{2}$ ). Belt transects provide a better estimate of large, sparser organisms than is provided by the $0.25-\mathrm{m}^{2}$ quadrats in transects, and were done sporadically prior to 1998 . Degrees of freedom for two-way ANOVA testing effect of site and year on sea star density (ln-transformed) were 1, 225 for site, and 12, 225 for year and site $\times$ year interaction. Original data for 1981, 1990, and 1994 values were no longer available, so values were estimated by eye from Figs. 2 and 3 in Menge et al. 1994 (1981 BB and 1990 SH) and Fig. 1A in Menge et al. (1997). Two-way ANOVA results are shown in the inset; data used were from 1998-2010. 


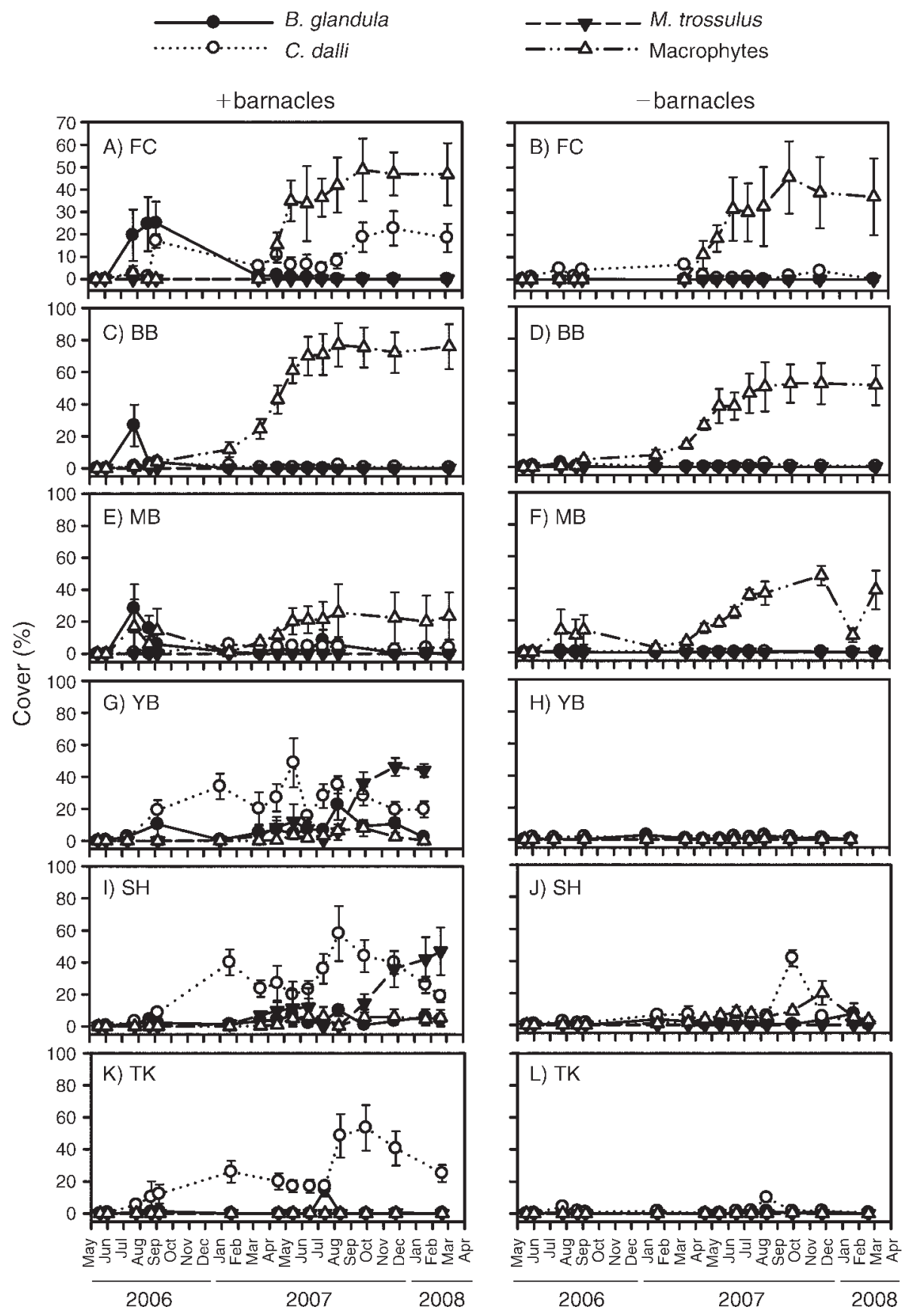

FIG. 9. Changes in abundance (mean percent cover $\pm \mathrm{SE}$ of the mean) of B. glandula, C. dalli, Mytilus trossulus, and macrophytes in experiments in which barnacle recruitment was allowed (+barnacle) and prevented (-barnacle). Experiments were carried out at six sites, shown arranged from north to south. Cape Foulweather sites were FC, BB, and MB, and Cape Perpetua sites were YB, SH, and TK. Predators (sea stars, whelks) had access to all plots.

until recently, they were consistently more abundant at $\mathrm{SH}$ that at BB. The temporally variable densities contrast to the relatively invariant predation rates, suggesting that functional responses (increase in per capita prey consumption with increasing prey; Holling 1959) or developmental responses (growth to larger sizes with more prey; Murdoch 1971) are important compo- nents of sea star predation rates. For example, like many sea stars, $P$. ochraceus can consume tens to hundreds of prey in a single "meal" (Paine 1974, Menge et al. 1994, Navarrete et al. 2000) and thus has the ability to increase its feeding rate if prey become abundant.

These considerations indicate that the capacity of the low intertidal food web to eliminate mussels evidently 
has varied little over a period of 18 years. Such relative stasis contrasts with the hypothesis of increasing predation capacity as an explanation for the minimal change in mussel abundance in the low zone. In fact, at SH at least, sea star abundance appears to be declining, which is the opposite of the pattern expected if predation was increasing through time.

\section{Hypothesis 2: facilitation}

This hypothesis was based on the observation that, as documented in at least three different rocky intertidal ecosystems, the prior occupancy of rock surfaces by barnacles was a powerful facilitator of mussel colonization. In New England, Oregon, and Argentina, mussels failed to colonize surfaces with acorn barnacles removed (Semibalanus balanoides, B. glandula, and S. balanoides, respectively) and colonized surfaces with barnacles present (Menge 1976, Berlow 1997, Bertness et al. 2006). A similar mechanism has been suggested for mussel-barnacle interactions in Chile (Navarrete and Castilla 1990). These observations suggested the first step of our study, examination of barnacle recruitment dynamics. To determine if the supply of potential facilitators had responded to climate in ways similar to that of mussels, we analyzed two aspects of barnacle recruitment: differences between pre-2000 and post-2000 periods, and responses to climate cycles.

Recruitment.-Barnacle recruitment was weakly responsive at best to the multiple climatic shifts that coincided during 1997-2000 (strong El Nino shifting to strong La Nina, warm PDO shifting to cool PDO, NPGO shifting to a windier phase). As shown in more detail in Menge et al. 2011, these patterns generally were consistent across latitudinal space. To a much smaller extent than mussels, each of these two species of barnacle tends to settle in more similar abundances among sites, and have been doing so since at least 1989 at the two longest-studied sites. Analysis of mid-zone $B$. glandula monthly mean recruitment at $\mathrm{BB}$ and $\mathrm{SH}$ from 1989 to 2008 indicated that the primary source of variation was among years (two-way ANOVA; year effect, $P=0.007)$, with no difference between sites $(P=$ 0.93). A similar result obtained for $C$. dalli (two-way ANOVA; year effect, $P<0.0001$, site effect $P=0.21$; see also Appendix A: Fig. A3). The patterns observed in the low zone were similar (Figs. 2, 4, 5).

Climate-recruitment relationships.-The linear regression analyses suggest that recruitment of $B$. glandula was influenced by ENSO and NPGO, and recruitment of $C$. dalli was influenced by ENSO and PDO (Fig. 6). In the significant relationships, however, little of the variance is explained (from $2 \%$ to $5 \%$ ), suggesting a weaker response of barnacles to climate variability than that of mussels $(\sim 13 \%$ of the variance explained by NPGO; Menge et al. 2009).

Since the analyses presented here and in Menge et al. (2009), we have reanalyzed the barnacle and recruitment data in more detail using multiple regression, quantile regression, and wavelet analysis (Menge et al. 2011). Multiple regression provided estimates of the total amount of variance explained by the combined climate indices, quantile regression allows detection of how relationships can vary across the range of (e.g.) low to high recruitment, while wavelet analysis, a type of timeseries analysis that accommodates changing statistical parameters through time, allows detection of relationships between climate and recruitment at varying frequencies (months to years) through the time series (Menge et al. 2011). These "regional-scale" analyses (all data from all sites were combined) revealed that recruitment-climate relationships are complex, too much so to summarize here, but overall, explained about $37-40 \%$ of the variance in recruitment rates of the three taxa. They also indicated that, in contrast to the spatially and temporally variable, locally expressed, and documented patterns of recruitment shown here and in Menge et al. (2009, 2011), at the regional scale, each taxon responded similarly to large, basin-scale, climatic patterns.

This analysis also means that about $60 \%$ of the variance is unexplained, and most likely is explained by smaller, regional- to local-scale factors such as coastal currents, bottom and coastal topography, larval behavior, sea breezes, fronts between water masses, tidal change, waves, and upwelling (e.g., Farrell et al. 1991, Pineda 1991, Shanks and Brink 2005, Woodson et al. 2007, Rilov et al. 2008, Dudas et al. 2009, Morgan et al. 2009). Differential responses to these various smallerscale factors is the likely explanation underlying the divergent patterns of recruitment in space and time seen in mussels and barnacles along the Oregon coast (e.g., Menge et al. 2009, 2011; Figs. 2, 4, 5; Appendix A: Fig. A3). Thus, overall, we suggest that the contrasting patterns of recruitment of barnacles vs. mussels reflect an interaction between large, basin scale variation in climatic patterns of varying periodicities, and more local-scale and behavioral factors that determine the abundances at which recruits arrive on different shores. The latter evidently affect each taxon differently, leading to a pattern whereby barnacle recruitment varies more on interannual scales, while mussel recruitment varies interannually, interdecadally, and among sites, sometimes by orders of magnitude.

We conclude that compared to mussel recruitment, barnacle recruitment has remained relatively unchanged in the $2000 \mathrm{~s}$, and is more weakly responsive to local, regional, and climate variation. Thus, without a change in supply rate, we would expect no change in abundance of barnacle adults, and thus no change in the strength of facilitation. We address this possibility next.

Facilitation.-Berlow's (1997) experiments were carried out in the mid intertidal zone, within clearances in the $M$. californianus-dominated mussel bed. They showed that barnacles, primarily B. glandula, were strong facilitators of $M$. trossulus. Barnacles facilitate mussels by providing a heterogeneous substratum 
densely packed with tiny crevices favored by mussel recruits (see Appendix A: Fig. A5). As mussels grow, this positive interaction shifts to the negative effect of competition and dooms the underlying barnacles as the mussels smother them (e.g., Menge 1976, Berlow 1997).

The facilitation experiment tested the importance of this positive interaction in determining mussel abundance in the low intertidal zone. Results revealed that the importance of facilitation was context-dependent, varying among sites within capes (e.g., TK vs. SH and YB on Cape Perpetua) and between capes (Cape Foulweather vs. Cape Perpetua; Fig. 9). Thus, facilitation of mussels by barnacles was strong and important at YB and $\mathrm{SH}$ on Cape Perpetua, but did not occur at the other Cape Perpetua site (TK) or at any of the Cape Foulweather sites. YB and SH were the two sites that in 2006 and 2007 had the highest combined rates of mussel and barnacle recruitment (e.g., Appendix A: Fig. A4). In contrast, TK had high barnacle recruitment but low mussel recruitment (Appendix A: Fig. A4), suggesting that in addition to high barnacle abundance, relatively high mussel recruitment rates are a necessary condition for the development of dense mussel populations. Of the two Cape Foulweather sites with recruitment data, BB had low recruitment of all taxa, while FC had mussel recruitment comparable to $\mathrm{SH}$ in both years, and moderately high barnacle recruitment in 2007 .

If facilitation is important, and barnacle recruitment was similar at $\mathrm{BB}$ and $\mathrm{SH}$ both before and after the millennial transition (Figs. 3-5), why haven't mussels colonized both low zones (Fig. 1)? Consistent with the facilitation hypothesis, it is likely that the near absence of mussels of either species in the low zone at BB at least partly is due to a lack of barnacle success in colonizing the low zone at BB (e.g., Fig. 1B). We suggest that this lack of success is due to another interaction, preemptive competition by macrophytes, which prevents successful colonization of barnacle recruits. Inhibition of barnacle recruitment by macrophytes is a venerable concept (e.g., Hatton 1938, Lewis 1964, Menge 1976), and the high cover of macrophytes in the BB low zone compared to the $\mathrm{SH}$ low zone likely presents a major barrier to cyprids seeking attachment to rock.

Experimental results at all Cape Foulweather sites $(\mathrm{FC}, \mathrm{BB}, \mathrm{MB})$ are consistent with this interpretation (Fig. 9A-F; Appendix B: Table B7D). Macrophytes colonized at similar abundances and rates regardless of the presence of barnacle recruits. Further, in +barnacle plots, barnacle colonists were abundant only in the early stages of the experiment (summer and autumn 2006). High abundances of macrophytes had developed by summer and autumn 2007, and presumably inhibited recruitment and thus colonization by barnacles (Fig. 9A, C, E).

As was observed in prior experiments in the high and mid intertidal zones (Menge 2000), in the low intertidal zone, the two barnacle species responded differently to recruitment and post-recruitment factors. For example, annual rates of recruitment of B. glandula during 20062007 were consistently much higher than rates of recruitment of $C$. dalli (Appendix A: Fig. A4), yet except for brief peaks of relatively high abundance of $B$. glandula at Cape Foulweather sites in 2006 (Fig. 9), C. dalli was the most abundant barnacle colonist (Fig. 9A, C, E, G, I, K). We attribute this disconnect between recruitment input and subsequent abundances of these species to two factors: predation and differential growth rates. Recall that these experiments took place in the presence of sea stars and whelks, feeding individuals of which were regularly recorded in the photographs of the plots during the course of the experiment (B. Menge, personal observations). Consistent with earlier results (e.g., Paine 1981, Menge 2000, 2003), predation was focused on $B$. glandula. As a consequence, although $C$. dalli recruitment was lower, and colonists were often present in much lower numbers, they escaped predation, likely due to their relatively small size, and flattened shape, meaning that per individual, they provided less energetic payoff to both whelks and sea stars (Paine 1981). In addition to higher survival in the face of severe predation, $C$. dalli at Cape Perpetua sites likely also benefitted from the higher abundance of food in the form of phytoplankton in waters bathing these sites (e.g., Menge et al. 1997, 2004, 2009, Leslie et al. 2005, Barth et al. 2007). We have not quantified growth of $C$. dalli, but growth rates of Semibalanus cariosus (Sanford and Menge 2001) and of B. glandula (B. Menge; unpublished data) are higher at Cape Perpetua sites. Observations during the analysis of photographs in the facilitation experiments (B. Menge; personal observations) suggest that $C$. dalli reach larger sizes at Cape Perpetua sites, and that despite relatively low recruitment, are able to cover significant amounts of space through growth. We note that this takes place slowly, but that with higher growth rates at more productive sites and a temporary escape from predation $(C$. dalli are eventually killed by predators, particularly after other prey have become scarce), this small barnacle is able to facilitate recruitment and colonization by $M$. trossulus.

Our evidence from the low zone is thus consistent with hypothesis $\mathrm{H}_{2}$ : the abundance of mussels reflects the extent to which barnacles facilitate them. These results, with prior experiments removing barnacles independently of predators (Semibalanus balanoides [Menge 1976, Bertness et al. 2006], B. glandula [Berlow 1997]), suggest that facilitation of mussels by barnacles can be a key determinant of low intertidal community structure.

\section{Mid- vs. low-zone mussel bed dynamics}

Do these low-zone results have any bearing on the dynamics of mid-zone mussel beds, which are dominated by $M$. californianus (e.g., Appendix A: Fig. A1, Appendix B: Table B2)? At SH, in contrast to the spatial and temporal fluctuations, and to the slow increase in low-zone cover of $M$. trossulus, abundance of $M$. californianus in the mid-intertidal zone has 
gradually decreased during the past 20 years at a rate of about $-1.3 \%$ per year (Fig. 1). At BB, persistent trends were lacking, but mussel abundance sharply decreased in association with two El Niño events, 1997-1998 and 2009-2010. Thus, two mid-zone trends need explanation: the between-site differences in mussel loss and recovery, and the slow decline at $\mathrm{SH}$ vs. the lack of a long-term trend at $\mathrm{BB}$.

Mid-intertidal-zone mussel bed dynamics (e.g., Paine and Levin 1981, Wootton 2002) are somewhat more complex than those in the low zone (B. glandula/C. dalli followed by $M$. trossulus), so the likely explanation of these patterns likely is more involved. As noted in the Introduction, in Oregon, recovery to domination by $M$. californianus varies with coastal productivity, taking from approximately two to approximately seven years (Berlow 1997, Guichard et al. 2003, Navarrete 2006; B. Menge, unpublished data), and follows the sequence $B$. glandula followed by $M$. trossulus followed by $M$. californianus, often with $S$. cariosus and $P$. polymerus involved at intermediate-to-late successional stages.

The role of facilitation by barnacles is likely important in the mid intertidal zone, but is not the only mechanism by which $M$. californianus can regain dominance. Recent genetic evidence suggests that both mussel species settle at the same time in the mid intertidal, but in different proportions, with $M$. trossulus making up $\sim 90 \%$ of the total and $M$. californianus making up $\sim 10 \%$ of the total. As suggested by Wootton (2002), the gradual succession to dominance by $M$. californianus is likely due to their stronger defenses against predators than those of $M$. trossulus (e.g., Sanford and Worth 2009, 2010), coupled with a steady trickle of recruits. In addition to the facilitation provided by barnacles, which are the early colonists in mid-zone mussel bed disturbances (e.g., Paine and Levin 1981, Navarrete 1996, Berlow 1997, Wootton 2002), $M$. californianus also recruit to filamentous algae such as $E$. muricata and mussel byssal threads (Paine 1974). Our field experience and that of many others suggests that M. californianus also live longer (likely $10-20$ years in the mid intertidal zone) than $M$. trossulus (usually less than two years). Thus $M$. californianus likely owes its mid-zone dominance to a sequence of processes, including commingled recruitment with its congener (and likely co-facilitatition by barnacles), greater resistance in juvenile stages to predators (whelks, small sea stars Leptasterias hexactis), and the ability to live years to likely decades.

We suggest that between-site contrasts in mussel dynamics are driven by differences in topography and in cape-scale productivity. At $\mathrm{BB}$, the wave-exposed reef is a relatively homogeneous gently sloping bench, while at $\mathrm{SH}$, the topography is heterogeneous, consisting of outcrops separated by surge channels and pools. At BB mussels grow relatively slowly and form large, continuous, monolayer beds, while those at SH grow fast and form smaller, discontinuous, multilayer beds (e.g.,
Guichard et al. 2003, Menge et al. 2008). As suggested by Fig. 1 (see also Appendix A: Fig. A6), mature mussel beds at BB appear susceptible to major losses during unusually stormy winters. For example, the drop in mussel cover in the late 1990s (1997-1999) approximately coincides with the two winters $(1998,1999)$ in the 1990s having the highest mean monthly significant wave height (SWH; see Ruggiero et al. 2010: Fig. 2). As observed by Paine and Levin (1981), recovery of disturbances takes about seven years and results mostly from juvenile recolonization and growth (e.g., Guichard et al. 2003).

At $\mathrm{SH}$, disturbances on the smaller beds there tend to be smaller, likely due to both the relatively small sizes of continuous mussel beds, and the more heterogeneous topography, which may inhibit the peeling away of extensive areas of mussels. The SH mid-zone mussel bed recovers more quickly, in two to three years, perhaps because of the faster growth rate of mussels compared to Cape Foulweather sites, and to the many layers of mussels, which in combination likely hasten lateral reinvasion of gaps by adult mussels (e.g., Paine and Levin 1981, Guichard et al. 2003; B. Menge, unpublished data). We therefore suggest that the differential patterns of variation between BB and SH mid zones seen in Fig. 1 reflect the interaction between reef topography and cape-scale differences in food availability (phytoplankton concentration).

The second pattern, the gradual decline of mussel abundance at $\mathrm{SH}$, may be due to long-term increases in SWH (and thus in wave forces impinging on the shore). In a recent analysis of wave data from deep-water coastal moorings, Ruggiero et al. (2010) discovered that average SWH and particularly the height of the five highest SWHs has increased over the past 35 years. In light of this fact, a steady decline in mussel cover at $\mathrm{SH}$ makes sense; increasing rates of environmental perturbations should lead to decreasing abundance of mussels. As argued above, a relatively steady decrease seems more likely at a site like $\mathrm{SH}$, where the conditions may favor smaller disturbances and faster recovery, than at a site like $\mathrm{BB}$, where conditions may favor less frequent but more catastrophic losses and slower recovery.

\section{Predicting intertidal ecosystem responses to climate change}

Ecosystem responses to straightforward, climaterelated changes in key components or processes seem likely to be more difficult to predict than would be expected. In this system, the explanation for minimal responses to large increases in mussel recruitment likely resides in differential responses of other key components of the system, and how the species interaction matrix responds. We suggest that such nonlinearities may be general. That is, virtually all ecosystems include a complex web of species interactions, the different components of which are unlikely to respond uniformly to impacts of climate change (e.g., Schiel et al. 2004, 
Hall-Spencer et al. 2008, Wootton et al. 2008). Forecasting how ecosystems will change probably will require approaches that evaluate the relative stochasticity vs. determinism in species interaction webs as web components change differentially. If web dynamics lead to consistent outcomes, then forecasting may be feasible. If web dynamics are stochastic, predicting future patterns of ecosystem structure will be difficult.

Further complicating the likely success of forecasting change in this ecosystem, the relative insensitivity of barnacle recruitment to climate pattern may change as climate change continues to alter weather patterns in the oceans and on land. Trends at two of our sites (Fig. 3; Appendix A: Fig. A3; SR and $\mathrm{SH}$ ) suggest that $B$. glandula recruitment could be increasing. The likely changes that could result from these shifts seem clear. With increasing cover of $B$. glandula, mussel colonization in the low zone should increase, likely leading to a reduction in algal abundance (e.g., Paine 1966, 1974). With increases in the supply of prey, predator density may increase as well, and in general, the dynamics observed at CP sites (e.g., SH), with increased domination by sessile invertebrates and higher intensities of consumer-prey interactions in the low zone may spread to additional sites along the coast. At present however, the trends of change are still short, and the threshold abundances that would trigger such shifts are unknown. Continued investigation is warranted, and indeed is underway.

\section{Conclusions}

We conclude that the weak response or lack of response of mussel abundances to the dramatic increase in mussel recruitment in the 2000s was due in part to the relative insensitivity of barnacles to the processes that led to the increase in mussel recruitment. Although mussel recruitment was responsive to large, basin-scale, climatic fluctuations (NPGO; Menge et al. 2009), identifying the exact processes that drive local-scale barnacle recruitment awaits further analysis. These processes are currently under debate, and will likely include upwelling and other more local-scale variables, including internal waves, tidal change, larval behavior, and processes leading to retention of larvae close to shore (e.g., Dudas et al. 2009, Pineda et al. 2009, Shanks 2009). Overall, the implication is that the dynamics of rocky intertidal communities exhibit nonlinear, speciesspecific responses to both ocean-scale and local-scale physical and biological factors. Nonlinearity and crossscale variation in response to ecological and environmental processes seem likely to be general for terrestrial and freshwater ecosystems as well as marine ecosystems, making problematic forecasting how ecosystems will respond in the future.

\section{AcKNowledgments}

We thank B. Daley, G. Hudson, M. Foley, J. Pamplin, C. Carlson, M. Robart, C. Cardoni, G. Murphy, C. Pennington, and M. Poole for spearheading the recruitment studies, and the students of Marine Biology at OSU (Biology 450/451) for their efforts on community surveys. S. Dudas, S. Close, A. Iles, J. Rose, and three anonymous reviewers provided valuable comments on the manuscript. J. Sapp and M. Frenock provided assistance in data analysis. The research was supported in part by grants from NSF, the Andrew W. Mellon Foundation, and by endowment funds from the Wayne and Gladys Valley Foundation. This is contribution number 387 from PISCO, the Partnership for Interdisciplinary Studies of Coastal Oceans funded primarily by the Gordon and Betty Moore Foundation and the David and Lucile Packard Foundation.

\section{Literature Cited}

Barth, J. A., B. A. Menge, J. Lubchenco, F. Chan, J. M. Bane, A. R. Kirincich, M. A. McManus, K. J. Nielsen, S. D. Pierce, and L. Washburn. 2007. Delayed upwelling alters nearshore coastal ocean ecosystems in the northern California current. Proceedings of the National Academy of Sciences USA 104:3719-3724.

Bayne, B. L. 1964. Primary and secondary settlement of the mussel Mytilus edulis (L.) (Mollusca). Journal of Animal Ecology 33:513-523.

Berlow, E. L. 1997. From canalization to contingency: historical effects in a successional rocky intertidal community. Ecological Monographs 67:435-460.

Bertness, M. D., C. M. Crain, B. R. Silliman, M. C. Bazterrica, M. V. Reyna, F. Hidalgo, and J. K. Farina. 2006. The community structure of western Atlantic Patagonian rocky shores. Ecological Monographs 76:439-460.

Broitman, B. R., C. A. Blanchette, B. A. Menge, J. Lubchenco, C. Krenz, M. Foley, P. T. Raimondi, D. Lohse, and S. D. Gaines. 2008. Spatial and temporal patterns of invertebrate recruitment along the west coast of the United States. Ecological Monographs 78:403-421.

Connell, J. H. 1961. Effects of competition, predation by Thais lapillus, and other factors on natural populations of the barnacle Balanus balanoides. Ecological Monographs 31:61104.

Connell, J. H. 1985. The consequences of variation in initial settlement vs. post-settlement mortality in rocky intertidal communities. Journal of Experimental Marine Biology and Ecology 93:11-45.

Connolly, S. R., and J. Roughgarden. 1999. Increased recruitment of northeast Pacific barnacles during the 1997 El Niño. Limnology and Oceanography 44:466-469.

Dayton, P. K. 1971. Competition, disturbance, and community organization: the provision and subsequent utilization of space in a rocky intertidal community. Ecological Monographs 41:351-389.

Denny, M. W., and R. T. Paine. 1998. Celestial mechanics, sealevel changes, and intertidal ecology. Biological Bulletin 194:108-115.

Dethier, M. N., E. S. Graham, S. Cohen, and L. M. Tear. 1993. Visual versus random-point percent cover estimations: "objective" is not always better. Marine Ecology Progress Series 96:93-100.

Dudas, S. E. B. A. Grantham, R. Kirincich, B. A. Menge, J. Lubchenco, and J. A. Barth. 2009. Current reversals as determinants of intertidal recruitment on the central Oregon coast. ICES Journal of Marine Science 66:396-407.

Duran, L. R., and J. C. Castilla. 1989. Variation and persistence of the middle rocky intertidal community of central Chile, with and without human harvesting. Marine Biology 103:555-562.

Fairweather, P. G., A. J. Underwood, and M. J. Moran. 1984. Preliminary investigations of predation by the whelk Morula marginalba. Marine Ecology Progress Series 17:143-156.

Farrell, T. M., D. Bracher, and J. Roughgarden. 1991. Crossshelf transport causes recruitment to intertidal populations in 
central California, U.S.A. Limnology and Oceanography 36:279-288.

Glynn, P. W. 1988. El Niño-Southern Oscillation 1982-83: nearshore population, community and ecosystem responses. Annual Review of Ecology and Systematics 19:309-345.

Guichard, F., P. Halpin, G. W. Allison, J. Lubchenco, and B. A. Menge. 2003. Mussel disturbance dynamics: signatures of oceanographic forcing from local interactions. American Naturalist 161:889-904.

Hall-Spencer, J. M., R. Rodolfo-Metalpa, S. Martin, E. Ransome, M. Fine, S. M. Turner, S. J. Rowley, D. Tedesco, and M.-C. Buia. 2008. Volcanic carbon dioxide vents show ecosystem effects of ocean acidification. Nature 454:96-99.

Hatton, H. 1938. Essais de bionomie explicative sur quelques especes intercotidales d'algues et d'animaux. Annals of the Institute of Monaco 17:241-348.

Hoegh-Guldberg, O., and J. F. Bruno. 2010. The impact of climate change on the world's marine ecosystems. Science 328:1523-1528.

Holling, C. S. 1959. The components of predation as revealed by a study of small-mammal predation of the European pine sawfly. Canadian Entomologist 91:293-320.

Kavanaugh, M., K. J. Nielsen, F. Chan, B. A. Menge, R. M. Letelier, and L. M. Goodrich. 2009. Experimental assessment of the effects of shade on an intertidal kelp: do phytoplankton blooms inhibit growth of open-coast macroalgae? Limnology and Oceanography 54:276-288.

Leslie, H. M., E. N. Breck, F. Chan, B. A. Menge, and J. Lubchenco. 2005. Barnacle reproductive hotspots linked to nearshore ocean conditions. Proceedings of the National Academy of Sciences USA 102:10534-10539.

Lewis, J. R. 1964. The ecology of rocky shores. English Universities Press, London, UK.

Mauzey, K. P. 1966. Feeding behavior and reproductive cycles in Pisaster ochraceus. Biological Bulletin 131:127-144.

Menge, B. A. 1976. Organization of the New England rocky intertidal community: role of predation, competition and environmental heterogeneity. Ecological Monographs 46:355-393.

Menge, B. A. 1992. Community regulation: under what conditions are bottom-up factors important on rocky shores? Ecology 73:755-765.

Menge, B. A. 2000. Recruitment vs. post-recruitment processes as determinants of barnacle population abundance on Oregon rocky shores. Ecological Monographs 70:265-288.

Menge, B. A. 2003. The overriding importance of environmental context in determining the outcome of species deletion experiments. Pages 16-43 in P. Kareiva and S. A. Levin, editors. The importance of species: perspectives on expendability and triage. Princeton University Press, Princeton, New Jersey, USA.

Menge, B. A., E. L. Berlow, C. A. Blanchette, S. A. Navarrete, and S. B. Yamada. 1994. The keystone species concept: variation in interaction strength in a rocky intertidal habitat. Ecological Monographs 64:249-286.

Menge, B. A., C. A. Blanchette, P. Raimondi, T. L. Freidenburg, S. Gaines, J. Lubchenco, D. Lohse, G. Hudson, M. Foley, and J. Pamplin. 2004. Species interaction strength: testing model predictions along an upwelling gradient. Ecological Monographs 74:663-684.

Menge, B. A., F. Chan, and J. Lubchenco. 2008. Response of a rocky intertidal ecosystem engineer and community dominant to climate change. Ecology Letters 11:151-162.

Menge, B. A., F. Chan, K. J. Nielsen, E. Di Lorenzo, and J. Lubchenco. 2009. Climatic variation alters supply-side ecology: impact of climate patterns on phytoplankton and mussel recruitment. Ecological Monographs 79:379-395.

Menge, B. A., B. A. Daley, P. A. Wheeler, E. Dahlhoff, E. Sanford, and P. T. Strub. 1997. Benthic-pelagic links and rocky intertidal communities: bottom-up effects on top-down control? Proceedings of the National Academy of Sciences USA 94:14530-14535.

Menge, B. A., T. C. Gouhier, T. L. Freidenburg, and J. Lubchenco. 2011. Linking long-term, large-scale climatic and environmental variability to patterns of marine invertebrate recruitment: toward explaining "unexplained" variation. Journal of Experimental Marine Biology and Ecology 400, in press.

Menge, B. A., et al. 2003. Coastal oceanography sets the pace of rocky intertidal community dynamics. Proceedings of the National Academy of Sciences USA 100:12229-12234.

Morgan, S. G., J. L. Fisher, S. H. Miller, S. T. McAfee, and J. Largier. 2009. Nearshore larval retention in a region of strong upwelling and recruitment limitation. Ecology 90:3489-3502.

Murdoch, W. W. 1971. The developmental response of predators to changes in prey density. Ecology 52:132-137.

Navarrete, S. A. 1996. Variable predation: effects of whelks on a mid-intertidal successional community. Ecological Monographs 66:301-321.

Navarrete, S. A., and E. L. Berlow. 2006. Variable interaction strengths stabilize marine community pattern. Ecology Letters 9:526-536.

Navarrete, S. A., B. R. Broitman, E. A. Wieters, and J. C. Castilla. 2005. Scales of benthic-pelagic coupling and the intensity of species interactions: from recruitment limitation to top-down control. Proceedings of the National Academy of Sciences USA 102:18046-18051.

Navarrete, S. A., and J. C. Castilla. 1990. Barnacle walls as mediators of intertidal mussel recruitment: effects of patch size on the utilization of space. Marine Ecology Progress Series 68:113-119.

Navarrete, S. A., and B. A. Menge. 1996. Keystone predation and interaction strength: interactive effects of predators on their main prey. Ecological Monographs 66:409-429.

Navarrete, S. A., B. A. Menge, and B. A. Daley. 2000. Species interactions in intertidal food webs: prey or predation regulation of intermediate predators? Ecology 81:2264-2277.

Paine, R. T. 1966. Food web complexity and species diversity. American Naturalist 100:65-75.

Paine, R. T. 1971. A short-term experimental investigation of resource partitioning in a New Zealand rocky intertidal habitat. Ecology 52:1096-1106.

Paine, R. T. 1974. Intertidal community structure: experimental studies on the relationship between a dominant competitor and its principal predator. Oecologia 15:93-120.

Paine, R. T. 1981. Barnacle ecology: is competition important? Paleobiology 7:553-560.

Paine, R. T. 1986. Benthic community-water column coupling during the 1982-83 El Niño. Are community changes at high latitudes attributable to cause or coincidence? Limnology and Oceanography 31:351-360.

Paine, R. T., and S. A. Levin. 1981. Intertidal landscapes: disturbance and the dynamics of pattern. Ecological Monographs 51:145-178.

Paine, R. T., and A. C. Trimble. 2004. Abrupt community change on a rocky shore - biological mechanisms contributing to the potential formation of an alternative state. Ecology Letters 7:441-445.

Pineda, J. 1991. Predictable upwelling and the shoreward transport of planktonic larvae by internal tidal bores. Science 253:548-551.

Pineda, J., J. A. Hare, and S. Sponaugle. 2009. Larval transport and dispersal in the coastal ocean and consequences for population connectivity. Oceanography 20:22-39.

Rilov, G., S. E. Dudas, B. A. Menge, B. A. Grantham, J. Lubchenco, and D. R. Schiel. 2008. The surf zone: a semipermeable barrier to onshore recruitment of invertebrate larvae? Journal of Experimental Marine Biology and Ecology 361:59-74. 
Ruggiero, P., P. D. Komar, and J. C. Allan. 2010. Increasing wave heights and extreme value projections: the wave climate of the U.S. Pacific Northwest. Coastal Engineering 57:539552.

Sanford, E. 1999. Regulation of keystone predation by small changes in ocean temperature. Science 283:2095-2097.

Sanford, E., and B. A. Menge. 2001. Spatial and temporal variation in barnacle growth in a coastal upwelling system. Marine Ecology Progress Series 209:143-157.

Sanford, E., and D. J. Worth. 2009. Genetic differences among populations of a marine snail drive geography variation in predation. Ecology 90:3108-3118.

Sanford, E., and D. J. Worth. 2010. Local adaptation along a continuous coastline: prey recruitment drives differentiation in a predatory snail. Ecology 91:891-901.

Schiel, D. R., J. R. Steinbeck, and M. S. Foster. 2004. Ten years of induced ocean warming cause comprehensive changes in marine benthic communities. Ecology 85:1833-1839.

Shanks, A. L. 2009. Barnacle settlement versus recruitment as indicators of larval delivery. II. Time-series analysis and hypothesized delivery mechanisms. Marine Ecology Progress Series 385:217-226.
Shanks, A. L., and L. Brink. 2005. Upwelling, downwelling, and cross-shelf transport of bivalve larvae: test of a hypothesis. Marine Ecology Progress Series 302:1-12.

Tegner, M. J., and P. K. Dayton. 1987. El Niño effects on Southern California kelp forest communities. Advances in Ecological Research 17:243-279.

Witman, J. D., M. Brandt, and F. Smith. 2010. Coupling between subtidal prey and consumers along a mesoscale upwelling gradient in the Galapagos Islands. Ecological Monographs 80:153-177.

Woodson, C. B., et al. 2007. Local diurnal upwelling driven by sea breezes in northern Monterey Bay. Continental Shelf Research 27:2289-2302.

Wootton, J. T. 1994. Predicting direct and indirect effects: an integrated approach using experiments and path analysis. Ecology 75:151-165.

Wootton, J. T. 2002. Mechanisms of successional dynamics: consumers and the rise and fall of species dominance. Ecological Research 17:249-260.

Wootton, J. T., C. A. Pfister, and J. D. Forester. 2008. Dynamic patterns and ecological impacts of declining ocean $\mathrm{pH}$ in a high-resolution multi-year dataset. Proceedings of the $\mathrm{Na}-$ tional Academy of Sciences USA 105:18848-18853.

\section{APPENDIX A}

Photos and text describing an example of the formation and destruction of a large bed of the mussel Mytilus trossulus at a Cape Perpetua site, Tokatee Klootchman; a map showing study sites along the Oregon coast; and figures showing changes in abundance of two mussel species at two zones at two sites, annual recruitment rates of mussels and barnacles in the mid zone at Boiler Bay (BB) and Strawberry Hill (SH) from 1989-2008, barnacle and mussel recruitment during the period of the facilitation experiment, 2006-2007, photos showing barnacle and mussel abundances in the presence and absence of barnacles at an early successional stage, and a photo showing an extremely large disturbance at BB in the wave-exposed mid intertidal zone (Ecological Archives M081-017-A1).

\section{APPENDIX B}

Seven tables analyzing linear regressions between year and abundances of sessile taxa at Boiler Bay and Strawberry Hill from 1991-2010; linear regressions between year and abundance of two mussel species in the mid and low zones at BB and SH, 19912010; patterns of recruitment of three taxa in relation to site, zone, and decade; patterns of Balanus glandula recruitment in relation to decade and site, and year nested within decade; patterns of Chthamalus dalli recruitment in relation to decade and site, and year nested within decade; variation in predation rate between sites and across time; and responses of mussels, macrophytes, and barnacles to the presence and absence of barnacle recruits in a 2006-2008 experiment (Ecological Archives M081-017-A2). 